\title{
An Overview on Medicinal Perspective and Biological Behavior of Benzotriazole; Synthetic Study on Its Multifaceted Biological Activities
}

\author{
V.S. Anjana ${ }^{1}$ P. Manoj Kumar ${ }^{2}$ \\ ${ }^{1,2}$ Department of Pharmaceutical Chemistry, The Dale View College of Pharmacy and Research Centre, Punalal, \\ Thiruvananthapuram, Kerala \\ Corresponding Author: V. S. Anjana
}

\begin{abstract}
Benzotriazole (BTA) is a nitrogen containing heterocyclic derivative containing three nitrogen atoms at $1^{\text {st }}, 2^{\text {nd }}$ and $3^{\text {rd }}$ positions with chemical formula $\mathrm{C}_{6} \mathrm{H}_{5} \mathrm{~N}_{3}$. Benzotriazole and its derivatives have great significance in medicinal chemistry and these derivatives were used by several chemists for therapeutic conditions because it possessing a wide spectrum of pharmacological activities including anti bacterial, anti fungal, anti viral, anti inflammatory, anti hyperglycemic, anti hypertensive, anti cancer and analgesic activity. In this review, different synthetic methods for the preparation of benzotriazole, importance of benzotriazole derivatives in biomedical research, highlighting its biological behavior, versatile activities and Structure Activity Relationship (SAR) studies are described. This review will help the researchers to understand the structure activity relationships and improvise the concepts in their research field.
\end{abstract}

Keywords: Benzotriazole, Anti microbial, Anthelmintic, Analgesic, Anti mycobacterial, Anti viral, Anti oxidative, Anti tumor, Anti inflammatory, Anti hyperglycemia, Anti fungal, Anticonvulsant activity.

\section{INTRODUCTION}

Benzo-fused azoles are heterocyclic organic compounds which have a ring system containing three nitrogen atoms and fused benzene ring showing a variety of biological activities (Fig 1). Benzotriazoles derivatives are used as corrosion inhibitors, radioprotectors and photo stabilizers in the production of plastic, rubber and chemical fiber. Benzotriazole derivatives are important as a precursor in the synthesis of peptides, acid azides, in the synthesis of 3hydroxymethyl-2,3-dihydrobenzofurans and 3-hydroxymethylbenzofurans. It also acts as an electron-donor and as precursor of radicals which is easily insertable into different chemical structures through various reactions, such as condensation, addition reactions and benzotriazolylalkylation. ${ }^{[1-2]}$

The biological activities of benzotriazole is of immense use in the pharmaceutical field, choleretic, anti bacterial, anti fungal, anti protozoal, anti viral, anti oxidant, analgesic, anti inflammatory, anti hyperglycemia and anti proliferative agents.<smiles>c1ccc2[nH]nnc2c1</smiles>

Fig 1; Benzotriazole

\section{SYNTHESIS OF BENZOTRAZOLE}

The methods used for the synthesis of benzotriazole and their derivatives depend on the nature of benzotriazole.

\subsection{By Diazotization ${ }^{[4]}$}

Benzotriazole is synthesized by diazotization process employing benzene1,2-diamine, sodium nitrite and acetic acid. 
<smiles></smiles>

\subsection{1, 3-Dipolar Cylcoaddition Of Azides And Arynes ${ }^{[6]}$}<smiles>[R]=CC=Cc1cnn[nH]1</smiles>

$$
\begin{array}{|ll}
\hline \mathrm{R} & \mathrm{R}^{1} \\
\mathrm{EtO}_{2} \mathrm{CCH}_{2} & \mathrm{H} \\
\text { Cinnamyl } & \mathrm{H} \\
\text { p-Fluorobenzyl } & \mathrm{H}
\end{array}
$$

Arynes formed through fluoridepromoted ortho-elimination of $o$ (trimethylsilyl) aryl triflates can undergo cycloaddition with various azides to form substituted benzotriazoles.

\subsection{N-Alkylation Of Benzotriazole Under Solvent-Free Conditions ${ }^{[5]}$}

An efficient and solvent-free method for highly regioselective $\mathrm{N}$-alkylation of benzotriazole in the presence of $\mathrm{SiO}_{2}$, $\mathrm{K}_{2} \mathrm{CO}_{3}$ and tetrabutylammonium bromide (TBAB) under thermal and microwave conditions has been described in which 1alkyl benzotriazoles are obtained regioselectively. These are formed by cooling and stirring of benzene-1,2-diamine with carboxylic acid and this moiety possess anti fungal activity.

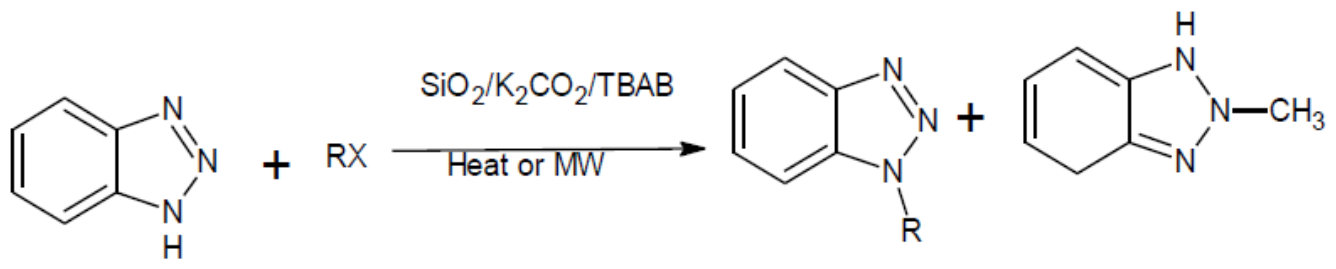

$\mathbf{R}=$ alkyl, aryl

\section{PROPERTIES OF}

BENZOTRIAZOLE ${ }^{[6,9]}$

MOLECULAR FORMULA: $\mathrm{C}_{6} \mathrm{H}_{5} \mathrm{~N}_{3}$

MOLECULAR WEIGHT: 119.124

COMPOSITION: C(60.50\%)

$\mathrm{H}(4.23 \%) \mathrm{N}(35.27 \%)$

MELTING POINT: $98.5-100^{\circ} \mathrm{C}$

BOILING POINT: $350{ }^{\circ} \mathrm{C}$

NATURE: White to brown crystalline powder

DENSITY: $1.36 \mathrm{~g} / \mathrm{cm}^{3}$

SOLUBILITY IN WATER: Soluble in water

\section{PHARMACOLOGICAL ACTIVITIES OF BENZOTRIAZOLE}

\section{1 vAnti microbial activity}

Sparatore and co-workers studied various nitrogen rings and reported that benzotriazole is part of heterocyclic systems. It possess biological activities, especially anti bacterial activity. ${ }^{[7-8]}$

In 1989 Sanna and co-workers reported the importance of benzotriazole moiety in triazolo[4,5-f]-quinolinone carboxylic acids (Fig 2), which is related to oxolinic acid. These compounds showed in vitro antimicrobial activity against Escherichia coli, with a Minimum Inhibitory Concentration (MIC) value. ${ }^{[9]}$<smiles></smiles>

$\mathrm{R}=\mathrm{H} / \mathrm{CH}_{3}$

Fig 2; General formula of triazolo[4,5-f]-quinolinone carboxylic acids derivatives.

Purohit and Srivastava synthesized a series of chlorosubstituted, phenoxyacetyl benzotriazoles (3a-e)(Fig 3) and all the compounds were screened for their antiinflammatory, analgesic, anti bacterial and anti fungal property. The compound $3 \mathrm{c}$ exerted analgesic effect and simple 
V. S. Anjana et.al. An overview on medicinal perspective and biological behavior of benzotriazole; synthetic study on its multifaceted biological activities.

benzotriazole nucleus possessed anti bacterial activity. ${ }^{[10]}$<smiles>[R]OCC(=O)n1nnc2ccccc21</smiles>

a) $4-\mathrm{Cl}-\mathrm{C}_{6} \mathrm{H}_{4}$ b) $2-\mathrm{Cl}-\mathrm{C}_{6} \mathrm{H}_{4}$ c) $2,5-\mathrm{Cl}-\mathrm{C}_{6} \mathrm{H}_{3}$

d) $2,4-\mathrm{Cl}-\mathrm{C}_{6} \mathrm{H}_{3}$ e) $2,4,6-\mathrm{Cl}-\mathrm{C}_{6} \mathrm{H}_{2}$

Fig 3; N-acyl-1H-benzotriazole derivatives

Similar anti microbial profile was reported for a series of 1-(1H-benzotriazol-1-yl)-2(heterocyclyl)ethanones (4a-f)(Fig. 4). ${ }^{[11]}$<smiles>[R2]C(=O)C([R])n1nnc2ccccc21</smiles>

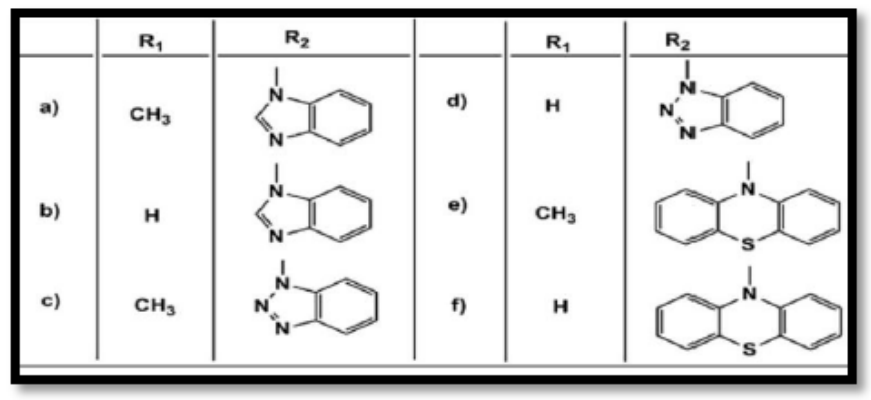

Fig 4; N-substituted 1H-benzotriazole derivatives endowed with antibacterial activity

Jamkhandi and coworkers prepared 1H-Benzotriazol-1-yl (2-hydroxy-5-[(E) phenyldiazenyl] phenyl) methanone derivatives through diazonium coupling

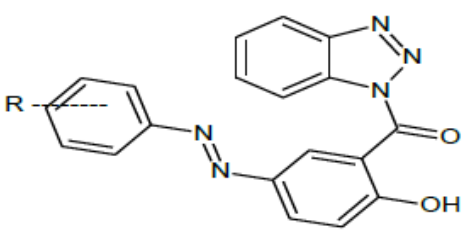

reaction and these derivatives showed good anti bacterial and anti fungal activity(5a-e) (Fig 5). ${ }^{[12]}$
a) $\mathrm{R}=\mathrm{H}$
b) $\mathrm{R}=4-\mathrm{COOH}$
c) $\mathrm{R}=4-\mathrm{Cl}$
d) $\mathrm{R}=4-\mathrm{NO}_{2}$
e) $\mathrm{R}=4-\mathrm{SO}_{2} \mathrm{NH}_{2}$

5 a-e

Fig 5; $1 H$-Benzotriazol-1-yl(2-hydroxy-5-[(E)phenyldiazenyl $]$ phenyl)methanone derivatives

In vitro anti bacterial activity of 5 halogenomethylsulfonylbenzotriazoles and benzimidazole ((Fig. 6) were reported by Ochal et al. These compounds were tested against a series of reference (Gram-positive and Gram-negative bacteria) and clinical strains (including methicillin-resistant (MRSA) and methicillin-sensitive (MSSA) Staphylococcus aureus strains). All the compounds showed significant anti bacterial activity, whereas benzimidazole derivatives possessing trifluromethyl substitution at $\mathrm{C}_{2}$ position were potent and able to inhibit
Staphylococci strains (MRSA) with MIC values $12.5-25 \mathrm{mg} / \mathrm{mL}^{[13]}$

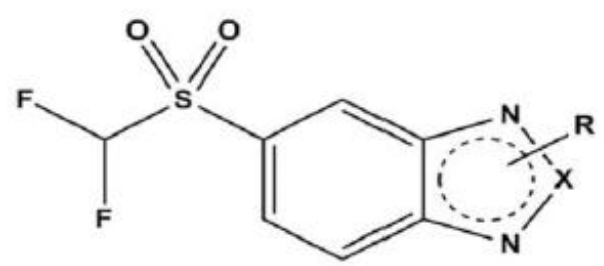

$\mathbf{X}=\mathbf{C}, \mathbf{N}$

Fig 6; General formula of difluoromethylsulfonylbenzotriazole and benzimidazole derivatives 
V. S. Anjana et.al. An overview on medicinal perspective and biological behavior of benzotriazole; synthetic study on its multifaceted biological activities.

In 2006, Swamy et al. prepared a series of $\mathrm{N}$-alkylated benzotriazole derivatives(7a-e) through microwaveassisted synthesis (Fig.7) and the anti bacterial activity of all compounds was tested against bacterial strains like Bacillus subtilis, Escherichia coli, Pseudomonas fluorescens, Xanthomonas campestris and Xanthomonas oryzae. They found that the anti bacterial behavior was probably due to the presence of bulky hydrophobic groups (cyano-biphenyl and benzodioxole) present in the compounds. ${ }^{[14]}$<smiles>c1ccc2[nH]nnc2c1</smiles><smiles>[R][R]O[Na]</smiles><smiles>[R]n1nnc2ccccc21</smiles>

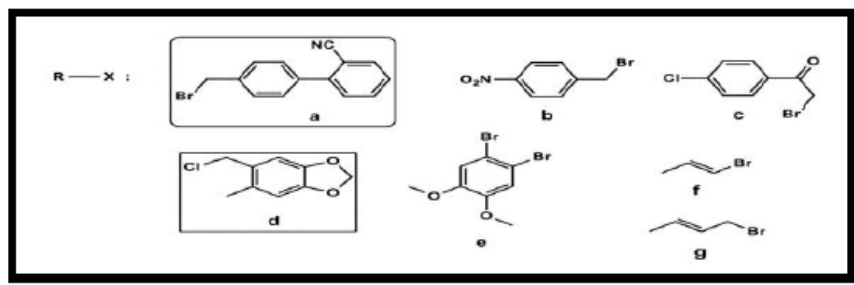

Fig 7; Microwave-assisted synthesis of $\mathrm{N}$-substituted benzotriazole derivatives

Suma et al synthesized (un)substituted-benzotriazoles containing N1 linked to substituted pyrazilidin-3,5dione moiety which showed anti microbial properties. All the synthesized compounds (8a-i)(Fig.8) were characterized and biologically evaluated by the cup plate diffusion method. Among this, the compound ( $8 \mathrm{~h})$ showed similar potency as that of Ciprofloxacin against Staphylococcus aureus, while limited activity was reported against Candida albicans. ${ }^{[15]}$<smiles>[R]c1ccc2nnn(CC(=O)N3C(=O)CC(=O)N3[R7])c2c1</smiles>
a) $\mathrm{R}=\mathrm{H}, \mathrm{R}_{1}=\mathrm{H} \quad$ b) $\mathrm{R}=\mathrm{H}, \mathrm{R}_{1}=\mathrm{C}_{6} \mathrm{H}_{6} \quad$ c) $\mathrm{R}=\mathrm{H}, \mathrm{R}_{1}=\mathrm{C}_{6} \mathrm{H}_{4} \mathrm{NO}_{2}$
d) $\mathrm{R}=\mathrm{H}, \mathrm{R}_{1}=\mathrm{C}_{6} \mathrm{H}_{4} \mathrm{Cl}$
e) $\mathrm{R}=\mathrm{Cl}, \mathrm{R}_{1}=\mathrm{H} \quad$ f) $\mathrm{R}=\mathrm{Cl}, \mathrm{R}_{1}=\mathrm{C}_{6} \mathrm{H}_{5}$
g) $\mathrm{R}=\mathrm{Cl}, \mathrm{R}_{1}=\mathrm{C}_{6} \mathrm{H}_{4} \mathrm{NO}_{2}$ h) $\mathrm{R}=\mathrm{Cl}, \mathrm{R}_{1}=\mathrm{C}_{6} \mathrm{H}_{4} \mathrm{Cl}$ i) $\mathrm{R}=\mathrm{NO}_{2}, \mathrm{R}_{1}=\mathrm{H}$

Fig 8; 1-(2-(1H-benzo[d][1,2,3]triazol-1-yl)acetyl)2-R1-pyrazolidine-3,5-dione derivatives

\section{Anthelmintic activity}

Sudhir and co-workers synthesized a series of benzotriazole-1-carbonyl-3,5arylformazans (9a-p) (Fig.9) under ultrasonic and solvent free conditions, all the compounds were tested for activity against adult earthworm Pheretima posthuma using mebendazole and albendazole as reference drugs. ${ }^{[16]}$

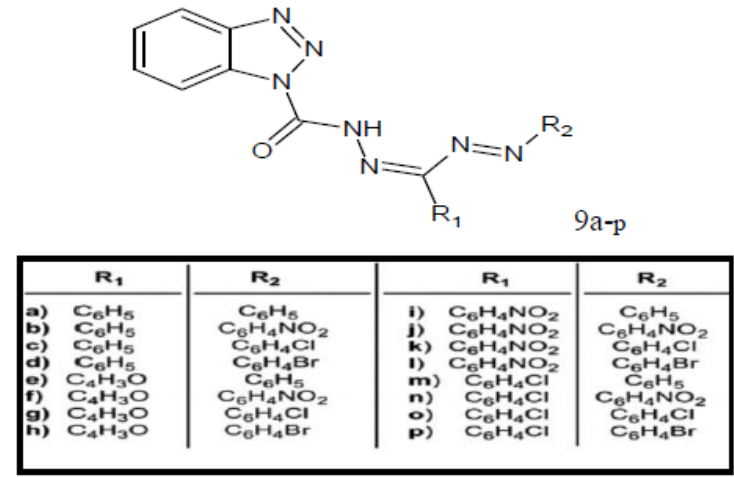

Fig 9; Benzotriazole derivatives 
V. S. Anjana et.al. An overview on medicinal perspective and biological behavior of benzotriazole; synthetic study on its multifaceted biological activities.

Although none of the tested compounds were effective than the reference drugs, derivatives $(9 \mathrm{~b}, \mathrm{f}, \mathrm{j}, \mathrm{n})$ showed dose-dependent anthelmintic activity because this behavior was attributed to the p-nitrophenyl substituent attached to azo group of benzotriazole moiety. The methyl benzo[d][1,2,3]triazole1-carboxylate was designed to be active against Necatur americanus infections but were totally inactive in newborn hamsters. $\mathrm{N}_{1}$ alkyl/aryl (11a-e) and alkoxy/aryloxy (12a-e) arylaminomethylene benzotriazole proved to be (Fig.10) good anthelmintic agents against Pheretima posthuma. ${ }^{[17]}$<smiles>C=C(c1ccccc1)c1ccc2nnn(C(=O)OC)c2c1</smiles><smiles>[R]OCn1nnc2ccccc21</smiles><smiles>[R]NCn1nnc2ccccc21</smiles>
a) $\mathrm{CH}_{2}-\mathrm{Ph}$
b) $\left(\mathrm{CH}_{2}\right)_{3} \mathrm{CH}_{3}$
c) $\left(\mathrm{C}_{2} \mathrm{H}_{4} \mathrm{OH}\right)_{2}$
d) $4-\mathrm{NO}_{2}-\mathrm{Ph}$
e) $2-\mathrm{CH}_{3}-\mathrm{Ph}$

Fig 10; Benzotriazole derivatives endowed with anthelmintic activity

\subsection{Analgesic activity}

A series of chlorosubstituted phenoxyacetyl and propionylbenzotriazoles were synthesised and evaluated for their analgesic activity. The 2,5-dichlorophenoxy acetyl benzotriazole (13) (Fig. 11) exhibited moderately better analgesic activity among the series. ${ }^{[18]}$

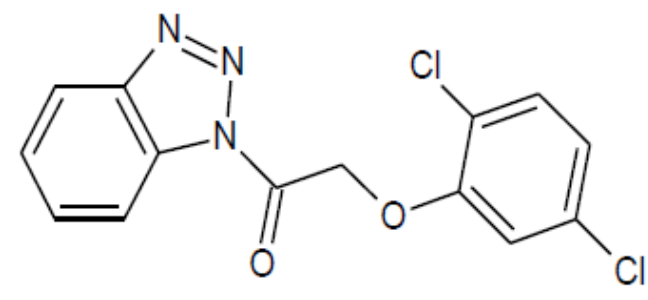

13

Fig 11; 2,5-dichlorophenoxy acetyl benzotriazole

5-Arylidene-2aryl-3(benzotriazoloacetamidyl)-1,3-thiazolidin-4ones derivatives were prepared from ethyl acetoacetate and evaluated for its analgesic activity by Eddy and Leimbach method. Compound $14 \mathrm{~h}, 14 \mathrm{i}$ and $14 \mathrm{j}$ were found to be better analgesic activity and acetylsalicylic acid was employed as reference $\operatorname{drug}\left(\right.$ Fig.12). ${ }^{[18]}$<smiles>O=C1/C(=C\c2ccccc2Br)SC(c2ccccc2Br)N1NC(=O)n1nnc2ccccc21</smiles>

$14 \mathrm{~h}$

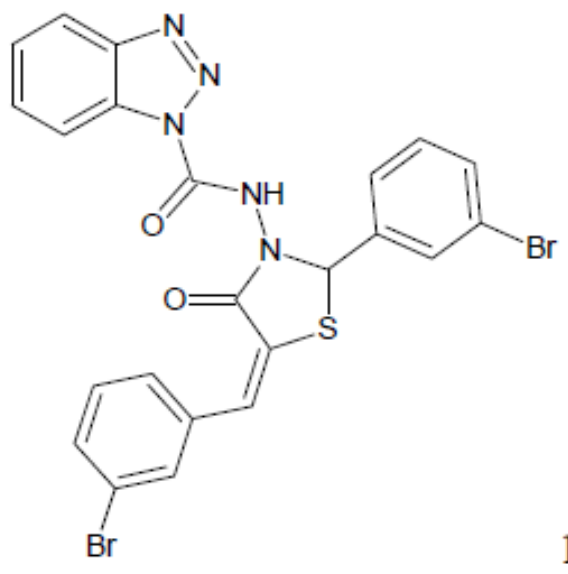

$14 \mathrm{i}$

Fig.12; Compound 14h and 14i 


\subsection{Anti mycobacterial Activity}

Carta and co-workers synthesized a series of 3-aryl substituted-2$(1 H(2 H)$ benzotriazol-1(2)-yl)acrylonitriles with the aim to identify the good substituents on the aryl moiety. 1substituted benzotriazole derivatives were more active than 2-benzotriazolyl isomers, while the unsubstituted phenyl moiety exhibiting the highest anti mycobacterial activity in vitro and also against Mycobacterium avium. The only exception is represented by 4-bromophenyl derivative, although its activity was lower than that of compound $15 \mathrm{a}$ shown in Fig $13 .{ }^{[19]}$

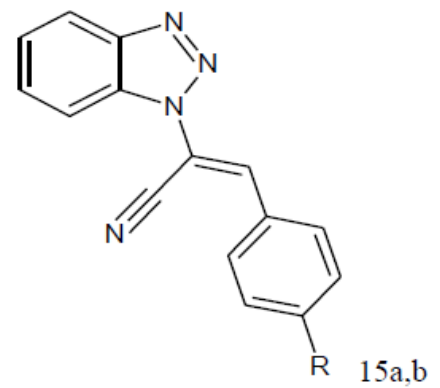
a) $\mathrm{R}=\mathrm{H}$ MIC $=6.25 \mathrm{mg} / \mathrm{mL}$
b) $\mathrm{R}=\mathrm{Br} \quad \mathrm{MIC}=12.5 \mathrm{mg} / \mathrm{mL}$

Fig13; 3-Aryl substituted-2-[1H(2H)benzotriazol-1(2)-yl]acrylonitriles and MIC values for compounds 15a,b

heteroaryl substituted-2-(1H(2H)benzotriazol-1(2)-yl)prop-2- enenitriles, prop-2-enamides and propenoic acids showed less activity because of their increased lipophilic character. This indicates that the steric hindrance and the nature of the substituents play an important role in the inhibition of Mycobacterium tuberculosis proliferation. ${ }^{[20]}$

Dubey et al. coupled benzotriazole nuclei with b-lactums and 2-azetidinones and checked for their antimicrobial activity. The 2-oxo-4-substituted aryl-azetidinone derivatives of benzotriazole were prepared by both conventional and microwave irradiation method and all the prepared compounds were tested against
Mycobacterium tuberculosis and other microorganisms. Ewa and co workers synthesized a series of benzotriazoles derivatives and their work was based on the anti mycobacterial activity of benzimidazole derivatives modified both in the heterocyclic core and in exocyclic constituents. The biological activity was enhanced by the introduction of a nitrobenzylsulfenyl group at second position and a substitution on the heterocycles benzene moiety with a halogen atom. ${ }^{[21,9]}$

Several new $o$-nitrobenzylated derivatives of halogenosubstituted 1hydroxybenzotriazoles (16a-p) where synthesized and their activity was tested against four Mycobacterium strains. ${ }^{[22]}$<smiles>[R3]c1c([R1])c([R1])c2c(nnn2OCc2cccc([2H])c2)c1[R]</smiles>

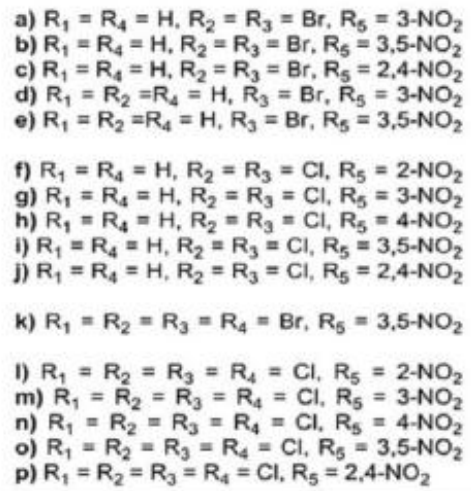

Fig 14; $o$-nitrobenzylated derivatives of halogenosubstituted 1-hydroxybenzotriazoles 
Carta et al. prepared a new series of $[1,2,3]$ Triazolo[4h,5h] and [4,5-f]quinolones with the purpose of synthesizing more potent and selective agents against Mycobacterium tuberculosis sensitive and resistant strains. They could synthesized triazolo[4,5-h]quinolone carboxylic acids which exhibited low $\mathrm{MIC}_{90}$ and the activity depended on the length and position of the substituent at triazole-nitrogen. Compounds bearing methyl group at $\mathrm{N}_{3}$ showed higher activity and they designed a series of 3methyl-9- substituted-6-oxo-6,9-dihydro$3 \mathrm{H}-[1,2,3]$-triazolo[4,5-h]quinolonecarboxylic acids (compound17). A variety of substituents on the quinolone nitrogen were introduced with the aim to improve the biological activity of the compound. ${ }^{[23]}$<smiles>[R]N1C=C(C(=O)O)C(=C)c2cc3c(cc21)nnn3C</smiles>

Fig.15; Chemical structure of 3,9-dimethyl-6-oxo-6,9-dihydro$3 \mathrm{H}-[1,2,3]$ triazolo[ $[4,5-\mathrm{h}]$ quinoline-7-carboxylic acid.

\subsection{Anti viral Activity}

Sakthi et al. reported derivatives of 4-(3H)-quinazoline having potential anti viral activity, especially against HIV-1 (IIIB) and HIV-2 (ROD) in MT-4 cells. The benzotriazole-substituted quinazoline derivative showed anti viral activity against IIIB by comparison with the standard drug azidothymidine compound 18 (Fig 16). ${ }^{[24]}$<smiles>O=c1c2ccccc2nc(-c2ccccc2)n1NCn1nnc2ccccc21</smiles>

Fig 16; Quinazolinone benzotriazole derivative as HIV inhibitor
Benzimidazole-substituted benzotriazole showed a significant anti viral effect on Respiratory Syncytial Virus (RSV) and it was more effective than azauridine (Fig. 17). This compound 19 was proved to be a potent RSV inhibitor. ${ }^{[25]}$

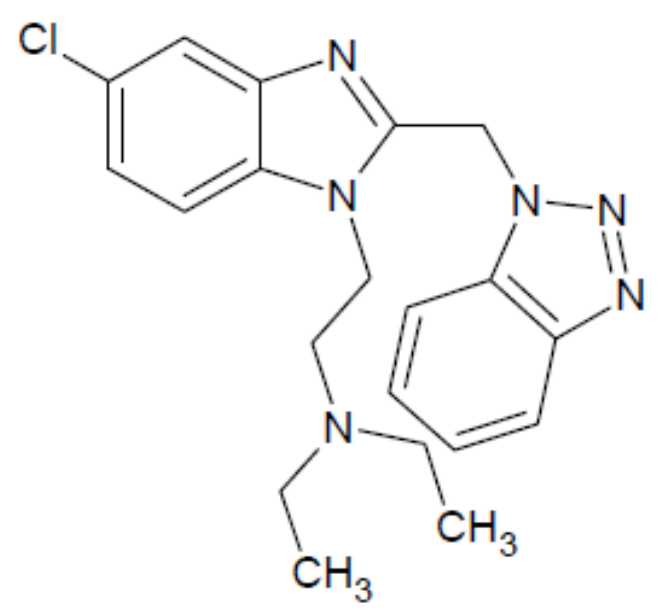

Fig 17; Benzimidazole-derivatized benzotriazole as RSV inhibitor

\subsection{Antioxidants}

Reducing agents that stabilize the free radicals produced by cellular metabolism or the compounds that inhibit oxidation are termed as antioxidants.

Benzotriazole-substituted

primaquine compound 21 showed a higher antioxidative interaction $(73.8 \%)$ than parent compound primaquine $(31 \%)$ which exhibited a good Lipoxygenase Inhibitory (LOX) activity (Fig 19). ${ }^{[27]}$

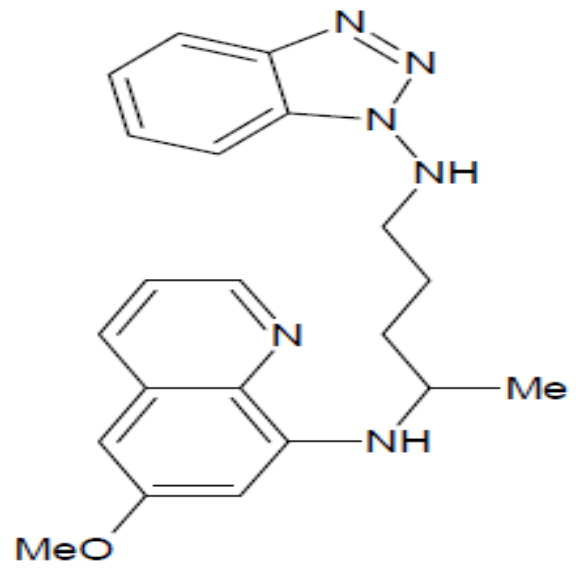

21

Fig 19; Benzotriazole derivatized drugs as antioxidants

Non-steroidal anti-inflammatory drug (NSAID) Ketoprofen, has an analgesic 
and antipyretic activities. Ketoprofen benzotriazole derivative exhibited a good interaction with 1,1-dipheny-1,2picrylhydrazyl (DPPH), which is a stable free radical with spared electron delocalization. The interaction between this derivative and DPPH indicated its radical scavenging ability in an iron free system, as well as its reductant character it also showed a high soybean lipoxygenase inhibition activity $(95 \%) .{ }^{[28]}$

\section{$\mathrm{N}_{1}$-Carbonyl-substituted}

benzotriazole derivative (22) has good DPPH interaction value of $85 \%$ as compared to the reference compound nordihydroguaiaretic acid which showed an interaction value of $91 \%$ at the same concentration (Fig. 20 ). So this derivative showed a good lipid peroxidation (LP) inhibition activity (31\%). Benzotriazole derivatives bearing a free phenolic and amine groups such as compound 23 were reported with a pronounced anti oxidant and anti ozonant activity. ${ }^{[29]}$
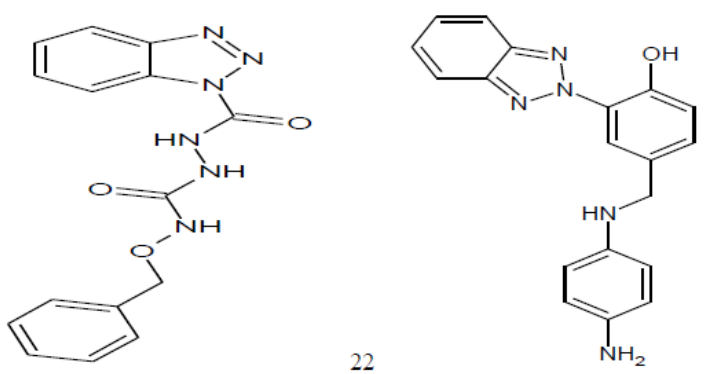

Fig 20; Benzotriazole-based antioxidants

\subsection{Anti tumor activity}

The therapeutic approach for the treatment of cancer diseases are different which includes surgical treatment, radiation therapy, immunotherapy or chemotherapy. Nowadays, a variety of anticancer drugs are in use such as alkylating agents, platinum complexes, porphyrin drugs, azole agents etc. Benzotriazole derivatives possess potent anticancer activity, vorozole(24), 4,5,6,7- tetrabromobenzotriazole (TBB) (25)(Fig. 21) are selective inhibitor of protein kinase CK2 and act as a potent anti cancer agent. ${ }^{[31]}$<smiles>Cn1nnc2ccc(C(c3ccc(Cl)cc3)n3nccn3)cc21</smiles><smiles>Brc1c(Br)c(Br)c2[nH]nnc2c1Br</smiles>

Fig 21; Benzotriazole-based cancer drugs

Al-Soud et al. combined several alkylated benzotriazoles with 1,2,4 triazole nuclei and they performed its activity on several human tumor cell lines. Compound (27) showed micro molar activity against leukemic, ovarian and renal tumor cells. ${ }^{[30]}$

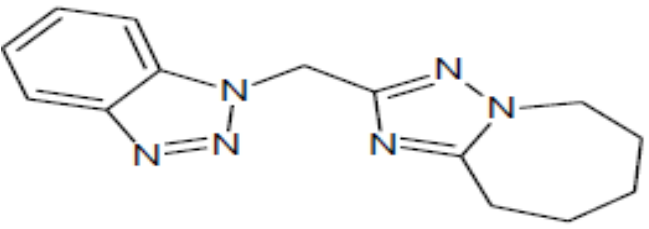

Fig 22; Benzotriazol-1(2)-yl)-tetrahydro-triazoloazepine.

Wan and co-workers synthesized 3(1H-benzo[d][1,2,3]triazol-1-yl)-1-(4methoxyphenyl)-1-oxopropan-2-benzoate $(\mathrm{BmOB})$ showed anti proliferative activity on cell lines derived from different tumor types and its analyses carried out on BEL7402 hepatocellular carcinoma cells. They also found (E)-2-(1H-benzo[d][1,2,3]triazol1-yl)-3-(4-methoxyphenyl) acrylonitrile (Fig.23) showed activity 100 times more than 6-mercaptopurine. ${ }^{[32]}$

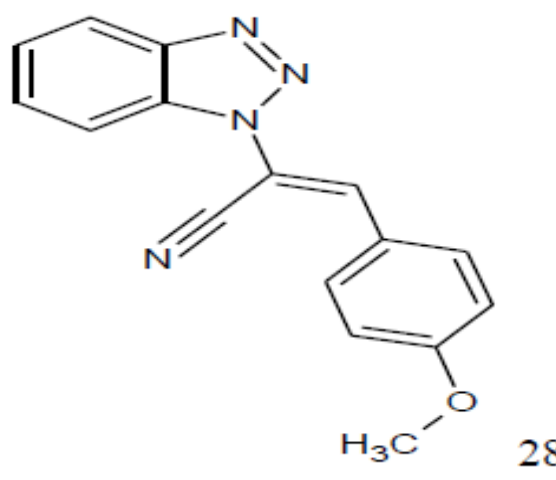

Fig 23

Zhang and colleagues synthesized 1,3,4-oxadiazole derivatives containing benzotriazole moiety showed potent anti tumor activity and their biological target 
was identified in the Focal Adhesion Kinase (FAK), a non-receptor tyrosine kinase that plays an important role in cell proliferation process. Compound 29 displayed good anti proliferative activity against MCF-7 cells and showed FAK inhibitory activity (comparable to the reference drug cisplatin). ${ }^{[9]}$<smiles>Fc1ccccc1CSc1nnc(Cn2nnc3ccccc32)o1</smiles>

Fig24; $\quad$ 2-((1H-benzo[d][1,2,3]triazol-1-yl)methyl)-5-((2fluorobenzyl)thio)-1,3,4-oxadiazole

\subsection{Anti-inflammatory Activity}

Anti-inflammatory is the property of a substance to reduces the inflammation or swelling. Benzotriazole-6carboxylicacid (30) displayed good cPLA2 $\alpha$ inhibition and potent anti-inflammatory activity (Fig.25). The replacement of the carboxyl benzotriazole scaffold by a carboxyl indole or a carboxyl benzimidazole moiety resulted in decreased antiinflammatory activity. ${ }^{[33]}$

Tetrazole-linked sulfanilamide benzotriazole derivative (31) displayed superior anti-inflammatory activity as compared to the standard drug paracetamol. The introduction of substituted sulfonyl moiety and benzotriazole increases the antiinflammatory activity of the compound. ${ }^{[34]}$
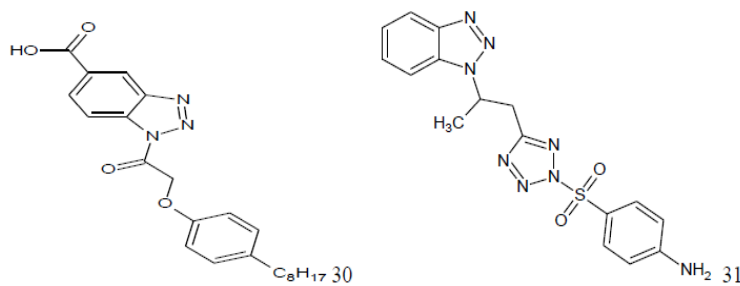

Fig 25; Benzotriazole-based anti-inflammatory agents

\subsection{Anti hyperglycemic Activity}

Benzotriazole-based

PTP1B

inhibitor showed anti hyperglycemic effects in animal models, along with oral bioavailability. Series of benzotriazole derivatives containing difluoromethylphoshonate (DFMP) moiety (compounds 32 and 33) showed PTP1B inhibitory activity at nanomolar level (Fig.26). ${ }^{[35]}$
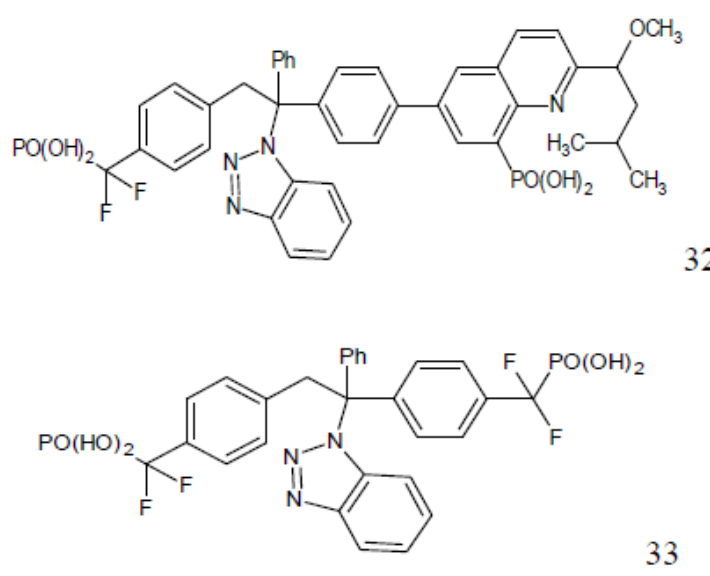

Fig26; Benzotriazole derivatives containing a difluoromethylphoshonates moiety as PTP1B inhibitors

Patel et al. synthesized tetrasubstituted benzotrazole-based PTP1B inhibitors containing difluoromethylphoshonate (DFMP) substituted naphthyl moiety (compound 34). All the synthesized compounds contained a benzotriazole ring, acetophenone and benzyl, naphthyl, or quinolinyl ring systems, substituted with difluoromethylsulfonamide (DFMS) which improve lipophilicity and oral efficacy of the compound. Compound 35 showed excellent anti-hyperglycemic effects in animal models and improved oral bioavailability, along with excellent selectivity over T-Cell Protein Tyrosine Phosphatase (TCPTP). ${ }^{[36]}$
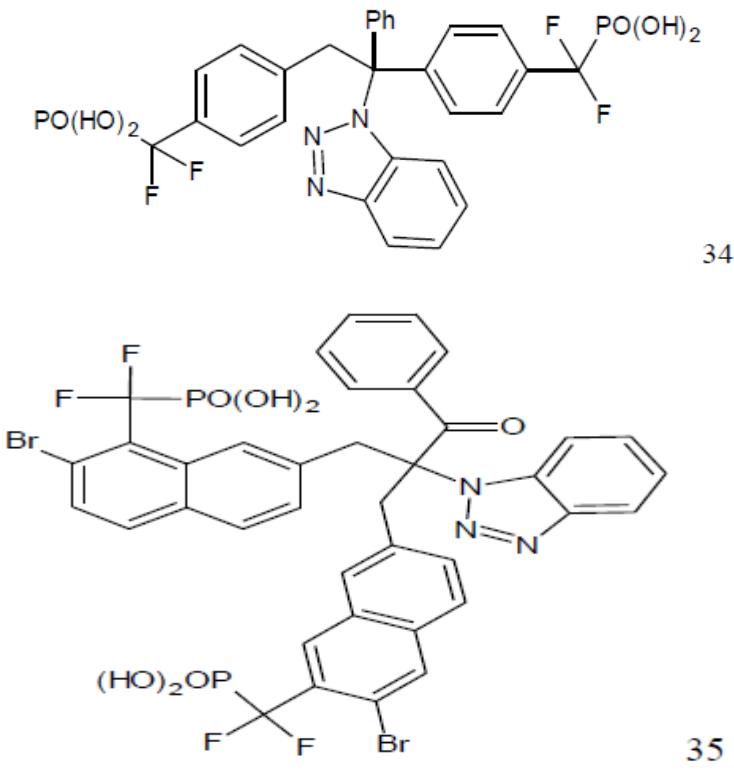

Fig 27; Benzotriazole derivatives containing a difluoromethylphoshonates moiety as PTP1B inhibitors. 


\subsection{Anti fungal activity}

Substituted 1,2,3-benzotriazole derivatives(36a-b) were synthesized from benzimidazoles with 1-chloromethyl benzotriazoles and evaluated its antifungal activity against Aspergillus niger and
Candida albicans by solidified agar method. Compound $36 \mathrm{~b}$ and e showed excellent anti fungal activity and its inhibitory activity was compared with griseofulvin (standard drug) (Fig. 28). ${ }^{[37]}$
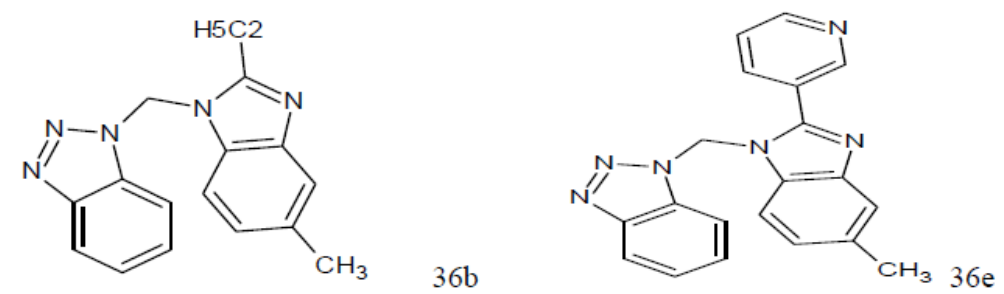

FIG. 28; Compound 36b and 36e

Benzotriazole derivatives containing pyrazolidinedione moiety (8a- i) were synthesized and their anti fungal activity was tested against Aspergillus niger and Candida albicans by cup plate diffusion method. Compounds 37e, 37h and<smiles>O=C1CC(=O)N(C(=O)Cn2nnc3ccc(Cl)cc32)N1</smiles>

37i (Fig. 29) were found to have potent activity against Aspergillus niger while compound 8c showed activity against Candida albicans. Drugs like Ketoconazole and Clotrimazole were used as standard drugs. ${ }^{[15,37]}$<smiles>O=C1CC(=O)N(C(=O)Cn2nnc3ccc([N+](=O)[O-])cc32)N1</smiles><smiles>O=C1CC(=O)N(c2ccccc2Cl)N1C(=O)Cn1nnc2ccc(Cl)cc21</smiles>

A series of $1 H$-1,2,3-benzotriazole derivatives were synthesized and evaluated for anti fungal activity against species of Candida. Compound 38a and 38c (Fig. 30) showed desirable anti fungal activity.
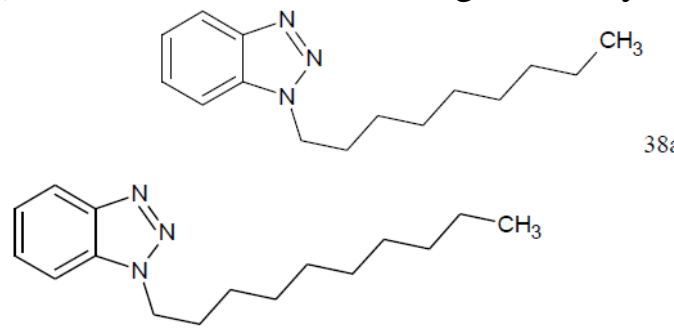

FIG. 30: Compound 38a and 38c

\subsection{Anti convulsant activity}

A series of benzotriazole containing 1,3,4-thiadiazole derivatives (39a-f) were synthesized and evaluated for the anti convulsant activity in Maximal Electroshock Seizure(MES) and Subcutaneous Metrazole Test (ScMet). Compounds 39a and 39d were found to be active in ScMet only, whereas the compounds 39c (Fig. 31) was active in MES. Activity of compound 39c was similar to the activity of Phenytoin and Valproic acid. ${ }^{[39]}$ 


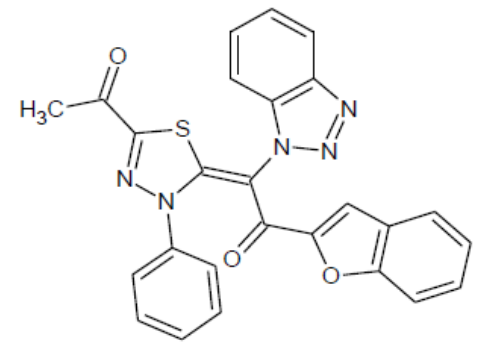

39 a<smiles>CC(=O)C1=NN(c2cccc(Cl)c2)/C(=C(\C(=O)c2cc3ccccc3o2)n2nnc3ccccc32)S1</smiles>

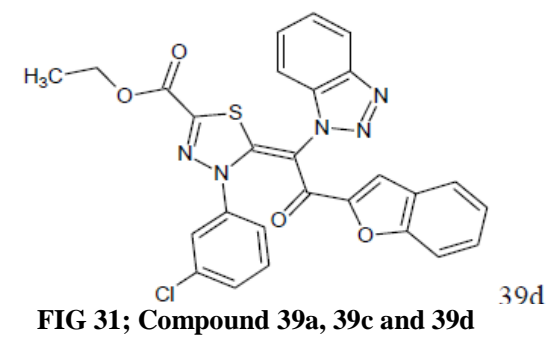

\subsection{Miscellaneous Uses}

Benzotriazole derivatives are used as ink components in oil-based marking pen. Water-soluble benzotriazole derivatives such as compounds 41, 42 were employed as components for water-thinned ink (Fig. 32) and benzotriazole-based azo dyes were used as dye stuff for hair (Fig. 33). ${ }^{[40]}$<smiles>[R]c1c([R])c([R3])c2c(nnn2[2H])c1[13CH]</smiles>

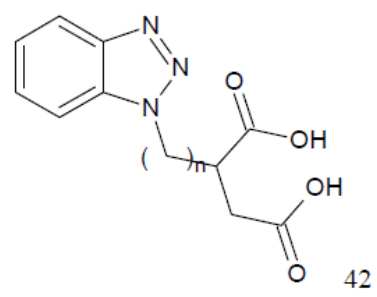

Fig 32; Benzotriazole derivatives used as ink components<smiles>Oc1ccc2ccccc2c1/N=N/c1ccc2[nH]nnc2c1</smiles>

Fig 33; Benzotriazole-based azo dye

\section{CONCLUSION}

Benzotriazoles are a class of bioactive heterocyclic compounds displayed a wide range of biological activities therefore; this nucleus appears a very interesting scaffold in the drug discovery and development processes. The biological profiles of new derivatives of benzotriazole would represent further development of better medicinal agents. Benzotriazole derivatives showed good biological activities such as anti bacterial, anti fungal, anti viral, anti cancer, anti mycobacterial, anti inflammatory, anti convulsant, analgesic, anti oxidant etc. The present review is about the benzotriazole derivatives and focused on its biological activities such as anti microbial, anthelmintic, analgesic, anti mycobacterial, anti viral, anti oxidative, anti tumor, anti inflammatory, anti hyperglycemia, anti fungal and anticonvulsant activity. This review suggests the possibility to synthesis a lead compound in which benzotriazole is used as a tagging molecule to produce new chemical entities of benzotriazole having good biological activities.

\section{ACKNOWLDGMENT}

I am highly indebted to my esteemed guide, Dr. P.Manoj Kumar, M.Pharm, Ph.D for his support, unending encouragement and advice, which helped me for the successful completion of this article.

\section{Conflict of Interest: None}

Source of Funding: None

Ethical Approval: Not Applicable 


\section{REFERENCES}

1. Suma B. V, Natesh N. N, Venkataramana C. H. S, Jays J, and Madhavan V: Synthesis And Antibacterial Of Some New 1, 2, 3 Benzotriazoles Derivatives Containing Pyrazolidinedione Moieties; International Journal of Pharmaceutical Sciences, 2012, 4,169-173.

2. Jamkhandi C.M, Disouza J I, Asgekar S D, Sutar TB and Kumbhar PS: Synthesis, Characterization, In-Vitro AntiInflammatory Activity And QSAR evaluation of benzotriazolyl-3-\{5(carboxymethyl) diazenyl $\}$ 2hydroxyphenyl prop-2-enoic acid derivatives; European journal of pharmaceutical and medical research, 2015, 2, 302-306.

3. Maisuradze M, Ugulava G, Bolkvadze N, Phalavandishvili G, Gaxokidze N, and Matnadze M: Some New Derivatives of 3H-Benzo Furo Benzotriazole; Journal of Chem. Eng, 2013, 7, 621-625.

4. Furmiss B.S, Hannaford AJ, Smith PWG, Tatchell AR: Vogel's Textbook Of Practical Organic Chemistry Pearson, 2008, 5, 1163.

5. Namdeo K.P, Singh V.K and Prajapati S.K: Synthesis of some 2-(substituted)-5[( $N$-benzotriazolomethyl)- $\quad 1,3,4-$ thiadiazolyl]-4-thiazolidinones for their antifungal activity; Indian J. Pharma. Educ. Res, 2009,3, 266-271.

6. B. V. Suma, N. N. Natesh and V. Madhavan: Benzotriazole in medicinal chemistry: An overview Journal of Chemical and Pharmaceutical Research , 2011,3,375-381

7. F. Sparatore, F. Pagani: Aminoalkyl derivatives of benzotriazole; Farm. Sci.1962,17,414-429.

8. F. Sparatore, F. Pagani : Aminoalkyl derivatives of benzotriazole. II; Farm. Sci. 20 1965, 17,248-258.

9. Briguglio, S. Piras, P. Corona, E. Gavini, M. Nieddu, G. Boatto, A. Cart Benzotriazole: An overview on its versatile biological behavior ; European Journal of Medicinal Chemistry, 2014, 137.
10. M. Purohit, S.K. Srivastava, Studies in aryloxylated benzotriazoles,; Indian J. Pharm. Sci. 54 ,1992, 25 -27.

11. R.K. Upadhyay, S.D. Srivastava, Synthesis and studies on biologically active mono and biheterocycles; Indian J. Pharm. Sci. 57,1995, 12-18.

12. C.M. Jamkhandi, J.I. Disouza, Synthesis and antimicrobial evaluation of $1 \mathrm{H}$ Benzotriazol-1-yl \{2-hydroxy-5[(E)phenyldiazenyl]phenyl \}methanone derivatives; Int. J. Pharm. Pharm. Sci. 5,2013, 225-228.

13. Z. Ochal, M. Bretner, R. Wolinowska, S. Tyski; Synthesis and in vitro antibacterial activity of 5halogenomethylsulfonyl-benzimidazole and benzotriazole derivatives; Med. Chem. 9, 2013, 1129-1136.

14. S. Nanjunda Swamy, Basappa, G. Sarala, B.S. Priya, S.L. Gaonkar, J. Shashidhara Prasad, K.S. Rangappa : Microwaveassisted synthesis of Nalkylated benzotriazole derivatives: antimicrobial studies; Bioorg. Med. Chem. Lett. 16 2006, 999-1004.

15. B.V. Suma, N.N. Natesh, C.H.S. Venkataramana, J. Jays, V. Madhavan: Synthesis and antibacterial of some new 1,2,3 benzotriazoles derivatives containing pyrazolidinedione moieties,; Int. J. Pharm. Pharm. Sci. 4,2012, 169173.

16. M.S. Sudhir, R. Venkata Nadh: Evaluation Of In Vitro Anthelmintic Activities Of Novel 1,2,3 Benzotriazole Derivatives Synthesized In Ultrasonic And Solvent Free Conditions; J. Pha. Res. 7, 2013, 47-52.

17. N.S. Pawar, D.S. Dalal, S.R. Shimpi, P.P. Mahulikar: Studies Of Antimicrobial Activity of $\mathrm{N}$-alkyl and N-acyl 2-(4thiazolyl)-1H-benzimidazoles; Eur. J. Pharm. Sci. 21,2004, 115-118

18. Asati K. C, Srivastava S. K, and Srivastava S. D : Synthesis of 5-arylidene2-aryl-3-(benzotriazoloacetamidyl)-1, 3thiazolidin-4-ones as analgesic and antimicrobial agents. Indian journal of chemistry, 2006, 45, 526-531.

19. P. Sanna, A. Carta, M.E. Nikookar: Synthesis And Antitubercular Activity of 
3- aryl substituted-2-[1H(2H)benzotriazol1(2)-yl]acrylonitriles; Eur. J. Med. Chem. 35, 2000, 535-543.

20. Carta, P. Sanna, M. Palomba, L. Vargiu, M. La Colla, R. Loddo: Synthesis And Antiproliferative Activity of 3-aryl-2-(1Hbenzotriazol-1-yl)acrylonitriles; Eur. J. Med. Chem. 2002, 891-900.

21. Dubey, S.K. Srivastava, S.D. Srivastava: Conventional and microwave assisted synthesis of 2-oxo-4-substituted arylazetidine derivatives of benzotriazole: a new class of biological compounds; Bioorg. Med. Chem. Lett. 21, 2011, 569573.

22. E. Augustynowicz-Kopec, Z. Zwolska, A. Orzeszko, Z. Kazimierczuk: Synthesis and antimycobacterial activity of selected nitrobenzyloxylated benzotriazoles; Acta Pol. Pharm. 65, 2008, 435-439.

23. Carta, M. Palomba, G. Paglietti, P. Molicotti, B. Paglietti, S. Cannas, S. Zanetti: [1,2,3]Triazolo[4,5-h]quinolones. A new class of potent antitubercular agents against multidrug resistant Mycobacterium tuberculosis strains; Bioorg. Med. Chem. Lett. 17,2007, 47914794.

24. Sakthi S, Periyasamy S, Sampath K, Clercq ED: Synthesis, anti-viral and cytotoxicity studies of some 2-phenyl-3substituted quinazolin-4-(3H)-ones; Int $\mathrm{J}$ Pharmacy Pharm 2, 2010, 71-79.

25. Tonelli M, Paglietti G, Boido V, Sparatore F, Marongiu F, Marongiu E, La Colla P, Loddo R;Antiviral Activity of Benzimidazole Derivatives. I. Antiviral Activity of 1-Substitute-- 2[(Benzotriazol-1-yl) methyl] benzimidazoles; Chem Biodivers 5,2008, 2386-2401.

26. Carta A, Loriga M, Piras S, Paglietti G, Ferrone M, Fermeglia M, Pricl S, Colla PL, Collu G, Sanna T: Synthesis And Anti-Picornaviridae In Vitro Activity Of A New Class Of Helicase Inhibitors The N,N0 -bis [4-(1H (2H)-benzotriazol-1 (2)yl) phenyl] alkyldicarboxamides; Med Chem 3,2009,520-532.

27. S imunovic , Perkovic' I, Zorc B, Ester K, Kralj M, Hadjipavlou-Litina D, Pontiki E : Urea and carbamate derivatives of primaquine: synthesis, cytostatic and antioxidant activities; Bioorg Med Chem 17, 2009, 5605-5613.

28. Perkovic I, Butula I, Kralj M, MartinKleiner I, Balzarini J, Hadjipavlou-Litina D, Katsori A-M, Zorc B : Novel NSAID 1-acyl-4-cycloalkyl/arylsemicarbazides and 1-acyl-5- benzyloxy/hydroxy carbamoylcarbazides as potential anticancer agents and antioxidants; Eur J Med Chem, 2012, 51, 227-238.

29. Jamkhandi CM, Disouza JI: Evaluation Of Antioxidant Activity For Some Benzotriazole Substituted With n-phenyl acetamide and acetyl carbamic acid derivatives. Int J Pharm Pharmsci 5,2013, 249-253.

30. Y.A. Al-Soud, N.A. Al-Masoudi, R. Ferwanah Ael: Synthesis and properties of new substituted 1,2,4-triazoles: Potential Antitumor Agents; Bioorg. Med. Chem. 11, 2003, 1701-1709.

31. Duncan JS, Gyenis L, Lenehan J, Bretner M, Graves LM, Haystead TA, Litchfield DW (2008): An Unbiased Evaluation Of CK2 Inhibitors By Chemoproteomics Characterization Of Inhibitor Effects On CK2 And Identification Of Novel Inhibitor Targets; Mol Cell Prot 7, 10771088.

32. J. Wan, C.L. Li, X.M. Li, S.S. Zhang: Synthesis, structure and biological activities of 2-(1H-1,2,3-benzotriazol-1yl)-1-(4-methylphenyl)-2-(1H-1, 2, 4triazol1-yl)-1-ethanone; Chem. Res. Chin. Univ. 22, 2006, 465-467.

33. Bovens S, Kaptur M, Elfringhoff ASc, Lehr M :1-(5-Carboxyindol-1-yl)propan2-ones as inhibitors of human cytosolic phospholipase A2 $\alpha$ : synthesis and properties of bioisosteric benzimidazole, benzotriazole and indazole analogues; Bioorg Med Chem Lett ,19, 2107-2111.

34. Rajasekaran A, Rajagopal K : Synthesis of some novel triazole derivatives as antinociceptive and anti-inflammatory agents.; Acta pharmaceutica ,2009,59, 355-364.

35. Y. Han, M. Belley, C.I. Bayly, J. Colucci, C. Dufresne, A. Giroux, C.K. Lau, Y. Leblanc, D. McKay, M. Therien, M.C. Wilson, K. Skorey, C.C. Chan, G. Scapin, 
V. S. Anjana et.al. An overview on medicinal perspective and biological behavior of benzotriazole; synthetic study on its multifaceted biological activities.

B.P. Kennedy: Discovery of [(3-bromo-7cyano-2-naphthyl)(difluoro)methyl]

phosphonic acid, a potent and orally active small molecule PTP1B inhibitor; Bioorg. Med. Chem. Lett. 18,2008, 32003205.

36. D. Patel, M. Jain, S.R. Shah, R. Bahekar, P. Jadav, B. Darji, Y. Siriki, D. Bandyopadhyay, A. Joharapurkar, S. Kshirsagar, H. Patel, M. Shaikh, K.V. Sairam, P. Patel,: Discovery of orally active, potent, and selective benzotriazolebased PTP1B inhibitors, Chem. Med. Chem. 6,2011,1011-1016.

37. Singh R. J: Syntheses of some new 1, 2, 3benzotriazoles as antimicrobial agents; Rasayan Journal of Chemistry 2009, 598601.
38. Khabnadideh S, Rezaei Z, Pakshir K., Zomorodian K, and Ghafari N: Synthesis And Antifungal Activity Of Benzimidazole, Benzotriazole And Aminothiazole Derivatives, Research Pharm. Science 2012,7, 65-72.

39. Shibata Y Oil-Based Marking Pens Using Aluminum Containers With Good Ink Resistance. JP 2014114335.

How to cite this article: V. S. Anjana, P. Manoj Kumar. An overview on medicinal perspective and biological behavior of benzotriazole; synthetic study on its multifaceted biological activities. International Journal of Research and Review. 2021; 8(5): 365-378. DOI: https:// doi.org/10.52403/ijrr.20210546 